JOURNAL OF SECURITY AND SUSTAINABILITY ISSUES

ISSN 2029-7017/ISSN 2029-7025 (online)

2020 Volume 9 January

http://doi.org/10.9770/jssi.2020.9.J(5)

\title{
Scopus
}

\section{THE ANTECEDENTS OF THE SAFETY PERFORMANCE IN THE CHEMICAL INDUSTRY OF THAILAND}

\author{
Thammarak Srimarut $^{1^{*}}$, Witthaya Mekhum ${ }^{2}$ \\ ${ }^{1,2}$ Suan Sunandha Rajabhat University, Bangkok, Thailand, \\ E-mails: $\underline{\text { I*thammarak.sr@ssru.ac.th }^{*} \text { Corresponding author), }{ }^{2} \text { witthaya.me@ssru.ac.th }}$
}

Received 10 March 2019; accepted 12 December 2019; published 30 January 2020

\begin{abstract}
The prime objective of the paper is to determine the antecedents of the safety climates in the chemical industry of Thailand. The study is of the view that the Safety climate has not been distinguished by some studies with safety performance along with rate of accidents for organizational safety performance. Therefore, it makes the concept of safety performance very limited. In the context of the Thailand and particularly the chemical industry of the Thailand it is among the pioneer study. The study has used the survey-based methodology and the response ate of the current study is turned out to be 57.3 percent. Findings of the study have revealed the fact that the employees' behavior, which improves their personal health and safety, is represented by safety compliance. The behavior of employees in a way, which improves the health and safety of co-workers along with support for the objectives and goals are represented by safety participation. Major compliance refers to comply with equipment for personal protection before starting work and throughout work. These safety practices are the responsibility of employees for reducing the chances of occupational accidents. Safety behavior is contributed by careless working behavior. Therefore, it may influence safety performance.
\end{abstract}

Keywords: safety climate; safety performance; chemical industry; Thailand

Reference to this paper should be made as follows: Srimarut, T., Mekhum, W. 2020. The antecedents of the safety performance in the chemical industry of Thailand. Journal of Security and Sustainability Issues, 9(January), 55-69. http://doi.org/10.9770/jssi.2020.9.J(5)

JEL Classifications: I15

\section{Background}

A major concern for several industries and organization is safety because of the direct and indirect cost associated with it (Jermsittiparsert, Sriyakul, Sutduean, \& Singsa, 2019). The safety of an organization is referred as the independence from any type of incidents arising from occupational activities (Robson et al., 2007). The conventional factors including rate of injury and accidents per month are used to access the performance of organizational safety. However, the measurements are not reliable and can deceive in organizational operations (Xu et al.,2018). Even if the rate of workplace's accidents is lower than the rate of accidents on road, this must not be ignored. The capital growth of a country is ensured by the manpower working in the organizations. Manpower is a key resource and engine for economy's growth. Several factors can be behind the workplace's accidents such as lack of skills and knowledge for a specific task, poor implementation of occupational safety and commitment of management, and lack of training. Because of these factors, there can be increase in the rate of accidents(Ogundipe et al., 2018). Therefore, the performance of organizational safety can be reduced.

Several indicators of performance have been added by some organization to determine the safety performance without analysis of accident. It is important to know that probability of accidents in future are reflected by the measurements of safety performance, as the stakes are high (Wehbe et al., 2016). Well-versed workers are not involved in accidents even high the job has high risks. The climate of an organization is referred as a construct with 


\section{JOURNAL OF SECURITY AND SUSTAINABILITY ISSUES}

ISSN 2029-7017/ISSN 2029-7025 (online)

2020 Volume 9 January

http://doi.org/10.9770/jssi.2020.9.J(5)

multi-dimensional in which different individual evaluation are done for the working environment. The dimensions included in this construct include safety perceptions, leadership, involvement in safety procedures, safety attitude, and commitment of employees and employers. Moreover, safety climate can be referred as a specific term, which is based on the value of safety perceptions of individuals the workplace(Chen et al., 2017). In the similar way, organizational performance can be influenced by safety climate, being its subsystem. The association between records of safety and safety climates in an organization was reported by Najjar et al.(2015). The researcher in his study identified that the dimensions of safety climate, which have been identified, can be improved by the analysis of perceived safely climate(Huang et al., 2016). The safety performance evaluation for different organization uses safety climates because it refers to the real scenario of organizational safety.

Safety climate has not been distinguished by some studies with safety performance along with rate of accidents for organizational safety performance. Therefore, it makes the concept of safety performance very limited. A scale of safety climate and safety performance was developed by Barbaranelli et al. (2015). The relation between safety performance and safety climate was analyzed using canonical correlation and product moment correlation. The findings of the study revealed that a significant and positive association exists between the two variables.

The relation between the general climates of organization has not been analyzed by any study since 2002 . Some other variables include the contributions made by organizational factors to safety behavior and safety climate, and minimal insights (Smith et al.,2018). In Thailand, the companies of food emulsification are not exempted from the safety hazards like any other organizations. In Thailand, the number of food emulsifier companies is limited in contrast to any other sector including construction, electronics, automotive, and metal works. Chemical industry of Thailand is operating in Thailand, which is a food emulsifiers company. In the industrial area of Penang Peri, the company is in operations since 1982. Since 1932, the company originated from Denmark. To date, the company has more than 7500 employees other than Denmark, who are working across the world such as Brazil China, USA, and India in the similar industry. The number of permanent employees is 148 and contract employees are 20 . There are foreigners from Myanmar, India, and Bangladesh.

The main operations of the companies involve manufacturing, maintenance, effluent treatments, Lab for Quality Control, and department facilities representing about $65 \%$ of total number of employees. Electric hazards, physical hazards, and chemical hazards can be involved in emulsifiers industries. The spray cooling, distillations, blending, chemical reactions, high-pressure steam, and packing by robots are involved in their processes. Therefore, it is suitable to conduct a study on analyzing the influence created on safety performance by safety climate in the Thailand industry of chemical (Jitwasinkul et al., 2016). The goal of the study can be the analysis of safety climate and safety performance at Thailand. The commitments, perceptions, participation, and attitude perceived by employees in their organization are indicated by the influence created on safety performance by safety climate. The major factors creating an influence on the safety performance between staff of operations can be identified by the study/ therefore, the risks of accidents can be reduced at workplace and safety environment of workplace can be improved (Lu \& Kuo, 2016).

The number of workplace's accident is still high as the number of hardware approaches is not sufficient for dealing with the workplace's accidents particularly when the errors are caused by humans(Carayon et al., 2015). A better understanding can be revealed for safety hazards at workplace by carrying out a proper research on safety performance. The study will help in developing new ideas to deal with such issue and ensure long-term organizational sustainability.

In 2006, it was mentioned by Clark that there is need for studying the safety climate dimensions because of its significance in analyzing the safety management and safety performance in an organization (Zhou et al., 2015). It 


\section{JOURNAL OF SECURITY AND SUSTAINABILITY ISSUES}

ISSN 2029-7017/ISSN 2029-7025 (online)

2020 Volume 9 January

http://doi.org/10.9770/jssi.2020.9.J(5)

is suitable to analyze the safety climates, which affect the safety performance between industry operators of emulsifiers in Thailand. These companies are exposed to different hazards in routine. In the context of Ukraine, Robinson (2017) found that almost 11.6\% accidents caused death when moving, rotating or spinning machines were being used by the workers. By analyzing the reasons for injury, it can be said that breach of production discipline and labor are the main reasons for accidents among the workers of Food Industry. The number of such accidents in the food industry of Thailand is not so high but is required to improve the safety performance and maintain it continuously.

\section{Literature Review}

\subsection{Safety Performance}

The way in which an organization manager its environment, health, safety, quality, and productivity affects its success and strength. Moreover, the organizational success is also based on the management of finance and marketing. The safety performance of an organization and employers' commitment is demonstrated by the environment, health, and safety measures of the organization (Montella \& Imbriani, 2015; Bernardi, 2019; Reinhold et al., 2019).

Safety performance comes under the overall organizational performance as stated by $\mathrm{Wu}$ and his colleagues (Wu et al., 2015). In 1997, Reason triggered the concept of safety performance and extreme resistance and extreme vulnerability for any type of hazards are two distinct parts of the safety performance. The way in which hazards are managed by an organization determines its safety. It was highlighted in a study conducted by Mullen et al. (2017) that safety climate of organizational behavior is linked with the health and safety performance. This in combination with a specific approach can improve safety performance in a significant way (Mullen et al., 2017). The robustness and resistance of an organization can be improved by enhancing safety performance, which can reduce the risk of accidents. Alternatively, the vulnerability of an organization can be increased by poor safety performance. Therefore, the risk of occurrence of accidents increases.

Safety organization, safety equipment, management, measures, gears, accident statistics, training for safety and evaluation, investigation of accidents, and training of practices can be used to evaluate the organizational safety performance (Mullen et al., 2017). In simple words, the quality of works related to safety such as efforts for achieving organizational safety are included in safety performance. The role of organizational management in ensuring a safe environment for employee's working is highlighted by safety performance. However, the organizational safety performance is determined by the participation and willingness of employees to involve in activities of safety (Fernández-Muñiz et al., 2017). Within the same context, it has been suggested by Siu et al. in 2004 that safety performance can be regarded as a reflector of workplace safety, which is employed for controlling workplace's accidents.

The organizational safety performance is determined by the number of accidents occurred in an organization (Wehbe et al., 2016). Further, it can be defined as compliance with the safety measures and participation of employees in such activities (Mullen et al., 2017). The personal belief of employees is based on their previous experiences. It is important to train the workers towards the right path by giving them proper safety skills training, motivation, and induction. Another study conducted by Montella and Imbriani (2015) on safety performance found that safety performance is not just about collection of statistics about accidents rather it is about the association between compliance of workers and their participation in the safety culture. 


\section{JOURNAL OF SECURITY AND SUSTAINABILITY ISSUES}

ISSN 2029-7017/ISSN 2029-7025 (online)

2020 Volume 9 January

http://doi.org/10.9770/jssi.2020.9.J(5)

\subsection{Safety Compliance}

The policies and efforts used by employers to make an organization safe are referred as safety compliance. These efforts may include performance of safety instructions and wearing equipment for personal protection (Smith et al., 2016). The policies and regulations for safety in Thailand have been designed to comply with the 1994 Act of Occupational Safety and Health. Compliance with the procedures of safety and working in a secure way are included in the safety compliance as per the researchers. A little different interpretation has been made by other researchers for safety compliance. For instance, safety compliance has been regarded by Buruck et al. (2016) as the employees' behavior to enhance the personal health and safety.

It has been mentioned by both researchers that adherence of workers to the procedures of safety by understanding the influence of personal health and safety matters is included in compliance. In order to deal with the work-related risks, the employees have to follow task performance before start of work. Language may become a constraint and miscommunication may occur in ensuring the adherence to safety procedures (Wehbe et al., 2016). All industries have been emphasized by Smith et al.(2016) on self-regulation, as people are responsible for ensuring compliance with safety procedures. The psychological, contextual, and behavioral factors are involved in ensuring safety compliance (Montella \& Imbriani, 2015).

\subsection{Safety Climate}

The significance of climate safety and its association with occupational safety has been developed in a number of industries. It can be regarded as the perceptions of individuals about the safety value in working environment or general perceptions of workers regarding safety (Hofmann et al., 2017). The safety climates are not similar for every. The researchers have argued that safety climate must be limited to the perception of workforce about the management or the way in which safety is reconciled with productivity by management (Casey et al., 2017).

Safety behavior can be predicted by safety climate, which is linked with the practices of safety, number of accidents, and compliance with OSHA. Therefore, to understand the safety performance, safety climate is a crucial variable. Moreover, it can be used as an indicator for unsecure working conditions. SEM approach was used by Smith et al.(2016) to test foundation and its association with components of organizational safety climate. The attitude of employees is a crucial reflector of safety climate. The attitude is based on a number of contributive factors within a working environment (Hofmann et al., 2017). It was stated by Buruck in a research that a set of safety measurement is included in safety climate, which is developed through recognizing the similarity among employees within an organization. It refers to the condition of safety at a specific place and time, which is not stable and changes with the dynamics of policies and environment (Buruck et al., 2016). Confusion arises related to the association and differences between safety climate and safety culture. Thus, safety climate can be used in pace of safety culture. To define safety climate in simple terms, it is can be said that it is not safety culture. Safety climate is formed by the perceived image of danger, safety, and risk of an organization.

\subsection{Management Safety Practices}

The strategies, processes, policies, and activities used by management to ensure the employee's safety are referred as management safety practices (Albrecht et al., 2015). Management safety practices are the basic element for pattern of safety climate that is developed between the employees since the time of its dissemination and improvements. A very significant influence is created by management safety practices on safety climate. This is because of its capability to reduce the rate of fatality at workplace including explosion, collisions, fire, etc. A study was conducted by a researcher in 2002 on Management Safety practices. The researcher incorporated training for 


\section{JOURNAL OF SECURITY AND SUSTAINABILITY ISSUES}

ISSN 2029-7017/ISSN 2029-7025 (online)

2020 Volume 9 January

http://doi.org/10.9770/jssi.2020.9.J(5)

safety, participation of worker, hiring practices, communication, and commitment of management as the Practices of Management while analyzing the environment of a hospital (Vredenburgh, 2002). The study was done to analyze the relevance of safety climate and practices of safety management. Therefore, in order to examine the influence of safety management practices on safety performance, it is important to incorporate it as a first dimension. Safety management practices may influence the safety climate in a number of ways.

The studies on safety climate have incorporate safety attitude as a key attribute. A strong influence is created on safety climate as some questions emerge about the way in which workplace safety is perceived by the workers (Albrecht et al., 2015). Share perceptions of policies, procedures, and practices of an organization are referred as psychosocial safety climate. These are originated from the practices of management. The perspectives from literature on psychosocial risk, work stress, and organizational climate constitute theoretical concept of psychosocial safety climate (Hofmann et al., 2017).

Another related construct, psychological safety, relates to team psychological climate, 'a shared belief held by a work team that the team is safe for interpersonal risk taking Vandekerkhof et al. (2018). Workers can freely engage in risk taking behavior by experiencing a team environment. In this way, learning takes place. The meaning of liberty is delivered by psychological safety from psychological harm that influences the safety and psychological health. Social and psychological harm can be generated by low PSC, which is a pre-prominent construct at work. Besides experiencing psychology safety, employees also related to psychological climate which a shared belief from teammates upon safety in interpersonal risk taking (Hu et al., 2018).

In past, studies have worked on analyzing the influence created on safety performance by safety training. The main focus of safety climate is on safety training as it is limited with low rate of accidents in companies working in container shipment industry (Wehbe et al., 2016). It was mentioned by Wehbe et al. (2016) that workers can use respiratory devices in the mining industry to protect their health. Moreover, effective safety training is also required to avoid any possible incidents. The issues are not addressed by the outcomes. Therefore, the training effectiveness is a crucial aspect. It is believed by employees that training is offered by the companies to perform job in a secure way Mullen et al.(2017). Training can be provided for specific skills of working and safety. Safety training can be perceived by workers as excellent without determining about the commitment of organization to safety. The efforts related to safety might be insufficient somewhere in the organization.

Interesting prospect is offered by such complexities and a standard should be set for safety training against the dimensions and components of safety. Because of lack of awareness about safety, new workers are involved in accidents at workplace (Chen et al., 2017). Training for safety induction can be used to create awareness among the workers. The workers are given introduction about the workplace hazards. Therefore, new workers must be orientated regarding the safety policy of the company, its operations, and layout of departments.

The important dimensions of safety climate were empirically tested by Kayes (2015) from the perspective of an operator. It was indicated by the findings that a significant influence is created by safety training on the organizational safety performance. It has been shown by previous studies that safety performance at different levels such as individual, group, and organization has positive association with safety climate. It was found by Yovi and Nurrochmat (2018) that companies with low rate of accident have well-associated safety training. Therefore, it is important to analyze the safety climate being an element of the safety climate. Previous research studies have stated that a positive influence is created by dimension of safety training on safety performance in organizational operations (Dobrzykowski et al., 2016). 


\section{JOURNAL OF SECURITY AND SUSTAINABILITY ISSUES}

ISSN 2029-7017/ISSN 2029-7025 (online)

2020 Volume 9 January

http://doi.org/10.9770/jssi.2020.9.J(5)

\subsection{Supervisors Safety Practices}

The safety practices of supervisor are the first and foremost component in the studies on safety climate, as per the questionnaire formulated by Hurtado et al. (2017). The supervisor characteristics are bias towards autocratic leadership; this reflects high control over the workforce. The workers follow the supervisor's directions knowing that they can come across accidents. The respondents were asked 9 questions in the survey to analyze the influence created on safety performance by safety climate.

It was indicated by Hurtado et al. (2017) that a crucial role is played by supervisors in ensuring a safety climate. For instance, Fang et al. (2015) offered a model in which safety influences of supervisors and managers were integrated. The research tested the model, which involved two central pathways. The first pathway was from politics in organization to support of manager for safety and its conditions. The second pathway was from fairness of supervisor to support of supervisor for safety and compliance with safety. A positive influence was found for safety support of management on safety support of supervisor (Yang, Zheng et al., 2019). It was concluded that safety conditions are influenced by management. However, the compliance of workplace with the regulations and rules of safety is affected by the perceived supervisor's fairness. It was found by Curcuruto and Griffin (2018) that safety commitment of supervisor determines the propensity of worker to take initiatives for safety and obey the rules. Some important influences can be created by supervisors related to the safety climate. It was found by Griffin and Curcuruto (2016) using a sample of three high-risk organizations in Spain that a crucial role is played by supervisors in preventing accident. This is done by transformation of the safety climate elements to the workforce members. A model was tested with causal chain running from safety climate to response of supervisor to response of co-workers to the attitude of worker. This further leads to behavior of safety, risk and then the incidents.

It was reported by Chen et al. (2017) that a negative influence can be created by supervisors on safety climate by developing a pressure on the workers. This conclusion was made by a study on the steel industry of US. Some of these concepts were studied by Beus et al.(2016) on the maintenance plant of Israel. The number of interactions related to safety between the workers and supervisors were measured by the researcher. The supervisors received performance feedback on weekly basis. Resultantly, there was increase in the number of interactions from 9 to $58 \%$. The number of accidents decreased significantly in the experimental groups by use of PPE (personal protective equipment) and earplugs. The perceptions of safety climate improved significantly as compared with the control groups with no change (Curcuruto \& Griffin, 2018). It was shown by the study that safety performance could be significantly improved by supervisors through use of PPE and emphasis on safety during interactions. Based on the literature reviewed the study has drawn the following hypothesis explaining the direct and indirect relationship between and among the variables.

H1: SCOM has significant impact on the MSP.

H2: SCLI has significant impact on the MSP.

H3: SCOM has significant impact on the SSP.

H4: SCLI has significant impact on the SSP.

H5: SCOM has significant impact on the SP.

H6: SCLI has significant impact on the SP.

H7: MSP has significant impact on the SP.

H8: SSP has significant impact on the SP.

H9: MSP mediates the relationship between SCOM and SP.

H10: MSP mediates the relationship between SCLI and SP.

H11: SSP mediates the relationship between SCOM and SP.

H12: SSP mediates the relationship between SCOM and SP. 


\section{Methodology}

To achieve the research objectives of current research, a structured questionnaire was developed to collect data using survey-based method. For analyzing the collected responses, structural equation modeling was chosen to carry out statistical procedure, also referred as a second-generation statistical technique, since first generation techniques involve some limitations. According to Gefen et al. (2000) Partial Least Square Structural Equation Modeling (PLSSEM) allows to simultaneously determine the interrelated series relationship through complex model estimation. In addition, it helps to integrate measurement errors and indicators to develop latent variables. Thus, it can be stated that SEM modeling, a second-generation method, is capable of exceeding the first generation limits (Hair et al.,2016). The response rate of the current study is 57.3 percent.

\section{Results}

Basically, SEM is used for testing the conceptual or theoretical model. Applying SEM enables to get significant insights and determine relationships among the latent variables. Structural equation modeling (SEM) combines the features of factor analysis and multiple regression to simultaneously analyze the multiple dependent relationships, thereby named as multivariate method (Hair et al., 2010). Gefen et al. (2000) suggest that other techniques, such as econometric modeling, classical test theory, covariance analysis, recursive and non-recursive path analysis, principal component analysis, and ANOVA can also be integrated through PLS. In case of multivariate data, such relationships can also be observed through path analysis, which show the linkages among dependent and latent variables (Gefen et al., 2000). For each construct, the uni-dimensionality, reliability and validity can also be assessed with the help of PLS technique, which in turn facilitate in the evaluation of measurement model. While determining the measurement model, four standards need to be considered for validity, including convergent and discriminant validity, as suggested by Hair et al. (2010). See Figure 1 and Table 1 below.

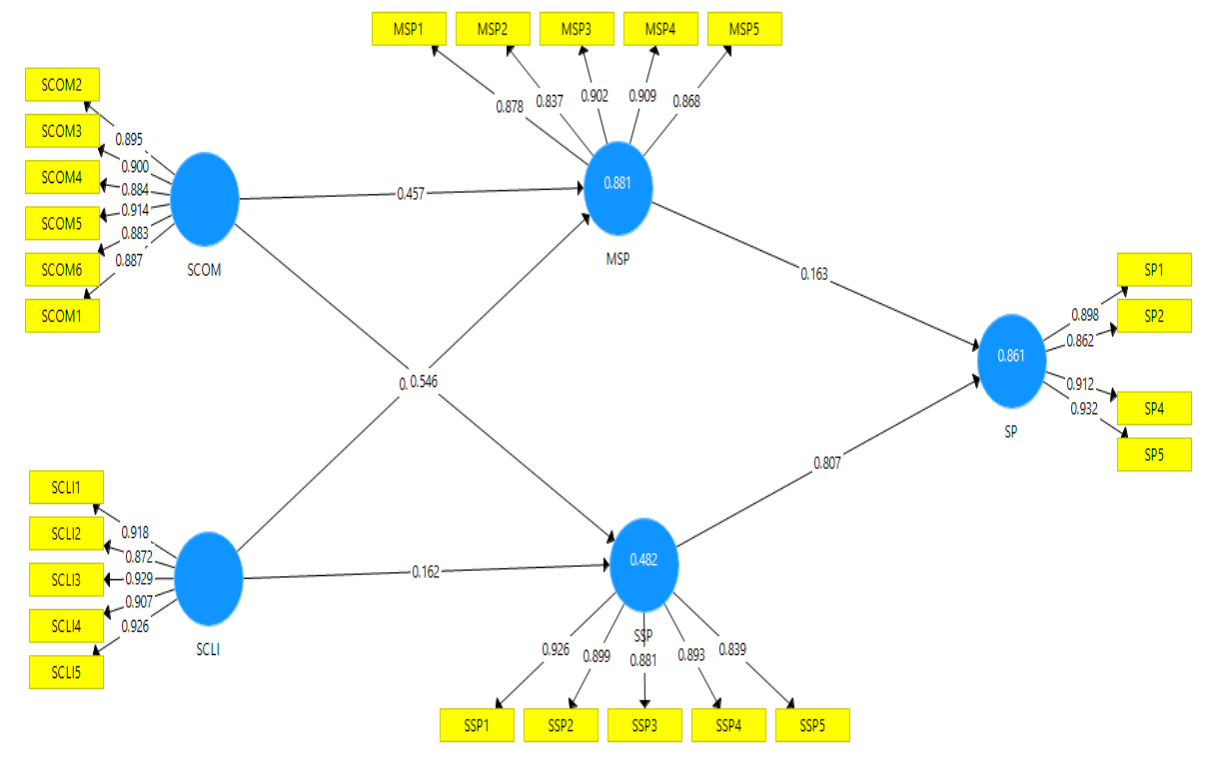

Figure 1. Measurement model 
JOURNAL OF SECURITY AND SUSTAINABILITY ISSUES

ISSN 2029-7017/ISSN 2029-7025 (online)

2020 Volume 9 January

http://doi.org/10.9770/jssi.2020.9.J(5)

Table 1. Outer Loadings

\begin{tabular}{|c|c|c|c|c|c|}
\hline & MSP & SCLI & SCOM & SP & SSP \\
\hline MSP1 & 0.878 & & & & \\
\hline MSP2 & 0.837 & & & & \\
\hline MSP3 & 0.902 & & & & \\
\hline MSP4 & 0.909 & & & & \\
\hline MSP5 & 0.868 & & & & \\
\hline SCLI1 & & 0.918 & & & \\
\hline SCLI2 & & 0.872 & & & \\
\hline $\begin{array}{l}\text { SCLI3 } \\
\end{array}$ & & 0.929 & & & \\
\hline SCLI4 & & 0.907 & & & \\
\hline SCLI5 & & 0.926 & & & \\
\hline SCOM2 & & & 0.895 & & \\
\hline SCOM3 & & & 0.900 & & \\
\hline SCOM4 & & & 0.884 & & \\
\hline SCOM5 & & & 0.914 & & \\
\hline SCOM6 & & & 0.883 & & \\
\hline SP1 & & & & 0.898 & \\
\hline SP2 & & & & 0.862 & \\
\hline SP4 & & & & 0.912 & \\
\hline SP5 & & & & 0.932 & \\
\hline SSP1 & & & & & 0.926 \\
\hline SSP2 & & & & & 0.899 \\
\hline SSP3 & & & & & 0.881 \\
\hline SSP4 & & & & & 0.893 \\
\hline SSP5 & & & & & 0.839 \\
\hline SCOM1 & & & 0.887 & & \\
\hline
\end{tabular}

(Cooper \& Schindler, 2008) defined convergent validity as the degree to which different scale scores are related to each other, since they are formulated to determine factor loadings of the similar construct. Although, the extent that several measuring items estimating similar construct exhibit high proportional change in common (Hair et al.,2016). To assess convergent validity, the present study examined the average variance extracted (AVE), composite reliability, and indicator's reliability. The composite reliability (CR) criterion determines the measuring items' internal reliability. (Henseler et al.,2012) mentioned that CR exhibits the level to which the latent variables are explained by the observed variables and is referred as Cronbach alpha. AVE indicates the degree or level at which several research items are in agreement towards measuring the same concept. The minimum acceptable cut-off range for AVE is equal or above 0.50, showing adequate level of convergent validity. Hair et al.(2016) suggest that AVE $>0.50$ indicates that on average, more than half of the change is explained by the latent variable. Thus, AVE value for this study turned out to be sufficient. Furthermore, it has been argued that at 0.708 factor loadings the AVE square root will turn out to be 0.50 . See Table 2 below. 
JOURNAL OF SECURITY AND SUSTAINABILITY ISSUES

ISSN 2029-7017/ISSN 2029-7025 (online)

2020 Volume 9 January

http://doi.org/10.9770/jssi.2020.9.J(5)

Table 2. Reliability

\begin{tabular}{|l|l|l|l|l|}
\hline & Cronbach's Alpha & rho_A & CR & (AVE) \\
\hline MSP & 0.926 & 0.927 & 0.944 & 0.773 \\
\hline SCLI & 0.948 & 0.950 & 0.960 & 0.829 \\
\hline SCOM & 0.950 & 0.950 & 0.960 & 0.799 \\
\hline SP & 0.923 & 0.924 & 0.945 & 0.813 \\
\hline SSP & 0.933 & 0.934 & 0.949 & 0.789 \\
\hline
\end{tabular}

The second main criteria that must be considered to determine the validity of measurement model is discriminant validity. In current research, the measurement model's validity is examined to assess if there is any difference among the two concepts which are theoretically different from each other (Henseler et al., 2012). In Gefen et al. (2000) study, discriminant validity is defined as the situation where two distinct concepts are also uncorrelated. Thus, Hair et al.(2016) suggested that two key measures were used in this research analysis to determine the DV i.e. 1) Fornell-Larcker criterion and 2) the cross-loadings. The Fornell-Larcker criterion suggests that there must be difference in the relation among construct and the square root of AVE's for the same constructs, in addition, the diagonal values must also exhibit higher values as compared to the corresponding constructs. Thus, for DV assessment, the second measure or criteria is the cross loadings, which require each indicator loadings to be greater than the other cross-loadings, to achieve adequate discriminant validity Hair et al. (2016). See Table 3 below.

Table 3. Validity

\begin{tabular}{|l|l|l|l|l|l|}
\hline & MSP & SCLI & SCOM & SP & SSP \\
\hline MSP & 0.879 & & & & \\
\hline SCLI & 0.816 & 0.901 & & & \\
\hline SCOM & 0.810 & 0.892 & 0.894 & & \\
\hline SP & 0.724 & 0.669 & 0.673 & 0.901 & \\
\hline SSP & 0.695 & 0.649 & 0.691 & 0.891 & 0.888 \\
\hline
\end{tabular}

For testing the research hypotheses, the present study also employed a structural model. Therefore, after verifying that whether appropriate measures are employed, it is important to present supporting evidence for the theoretical model, just like structural portion of the underlying model. Duarte and Raposo (2010) describe structural model as the breaking down of a linkage among the latent constructs. In order to examine structural model, the researcher must conform to different criteria for estimating the structural model, such as, observing path-coefficients' significance, coefficient of determination $\left(\mathrm{R}^{2}\right), \mathrm{t}$ and $\mathrm{p}$ statistics, and standard error.

Structural model is presented in Figure 2 below. 


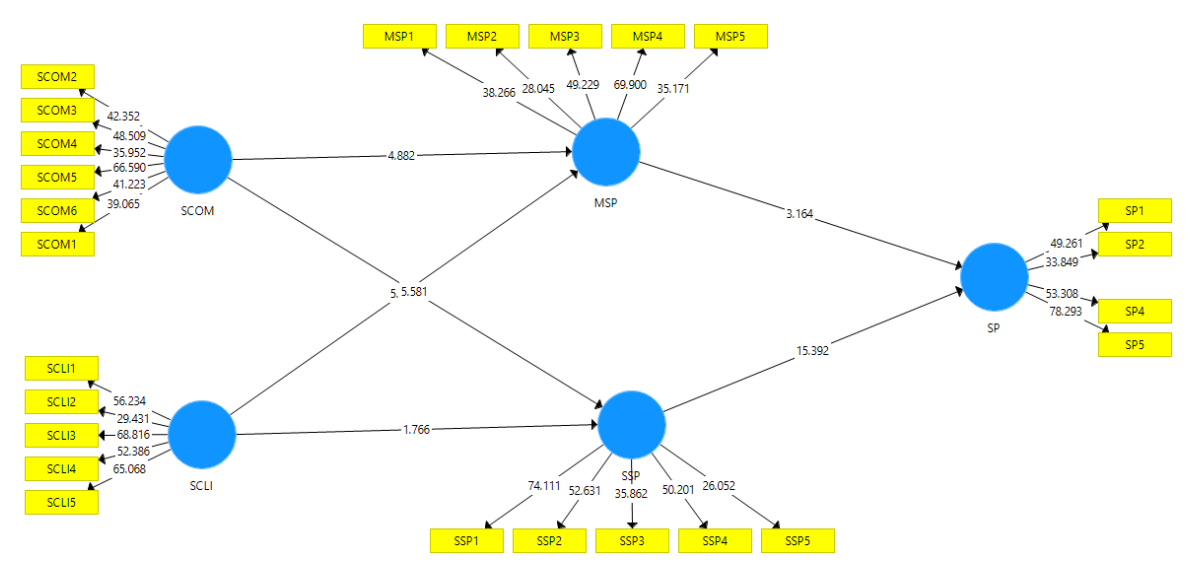

Figure 2. Structural Model

The findings of the study have provided support to all the proposed results. All the paths are significant at $\mathrm{p}$ value less than 0.05 . See Table 4.

Table 4. Direct Relationship

\begin{tabular}{|l|c|c|c|c|c|}
\hline & $(\mathbf{O})$ & $(\mathbf{M})$ & $($ STDEV $)$ & $(\mid \mathbf{O} /$ STDEV $\mid)$ & P Values \\
\hline MSP -> SP & 0.163 & 0.170 & 0.052 & 3.164 & $\mathbf{0 . 0 0 1}$ \\
\hline SCLI > MSP & 0.508 & 0.513 & 0.092 & 5.524 & $\mathbf{0 . 0 0 0}$ \\
\hline SCLI -> SP & 0.213 & 0.222 & 0.085 & 2.522 & $\mathbf{0 . 0 0 6}$ \\
\hline SCLI > SSP & 0.162 & 0.169 & 0.092 & 1.766 & $\mathbf{0 . 0 3 9}$ \\
\hline SCOM -> MSP & 0.457 & 0.452 & 0.094 & 4.882 & $\mathbf{0 . 0 0 0}$ \\
\hline SCOM -> SP & 0.516 & 0.507 & 0.084 & 6.108 & $\mathbf{0 . 0 0 0}$ \\
\hline SCOM -> SSP & 0.546 & 0.541 & 0.098 & 5.581 & $\mathbf{0 . 0 0 0}$ \\
\hline SSP > SP & 0.807 & 0.800 & 0.052 & 15.392 & $\mathbf{0 . 0 0 0}$ \\
\hline
\end{tabular}

The path estimating the mediating effect of the MSP and SSP are also significant at po value less than 0.056. See Table 5 below.

Table 5. Mediation

\begin{tabular}{|l|c|c|c|c|c|}
\hline & $(\mathbf{O})$ & $(\mathbf{M})$ & $($ STDEV $)$ & $(\mid \mathbf{O} /$ STDEV|) & P Values \\
\hline SCLI -> MSP -> SP & 0.083 & 0.088 & 0.032 & 2.562 & $\mathbf{0 . 0 0 5}$ \\
\hline SCOM -> MSP -> SP & 0.075 & 0.076 & 0.027 & 2.744 & $\mathbf{0 . 0 0 3}$ \\
\hline SCLI -> SSP -> SP & 0.131 & 0.135 & 0.073 & 1.778 & $\mathbf{0 . 0 3 8}$ \\
\hline SCOM -> SSP -> SP & 0.441 & 0.431 & 0.073 & 6.018 & $\mathbf{0 . 0 0 0}$ \\
\hline
\end{tabular}

One such mean to estimate structural model is through the estimation of coefficient of determination or R-square value (Duarte \& Raposo, 2010). The coefficient of determination significantly contributes to the research analysis and there are different perceptions regarding the R-square's value. In view of Duarte and Raposo (2010), the minimum range of R-square is above $1.5 \%$, while Cooper and Schindler (2008) suggested different ranges for describing $\mathrm{R}^{2}$ value, such as, if the $\mathrm{R}^{2}$ value falls between 0.02-0.12 it is referred as weak, if it falls between 0.13 0.25 , it is referred as moderate, and if it exhibits value greater than 0.26 then it is referred as substantial. Thus, the context or type of research highly influence the size of R-square. It is evident from Duarte and Raposo(2010) studies, who reported $\mathrm{R}^{2}$ values equal to 31.5 and 19.7 percent in their studies, respectively. See Table 6 below. 
JOURNAL OF SECURITY AND SUSTAINABILITY ISSUES

ISSN 2029-7017/ISSN 2029-7025 (online)

2020 Volume 9 January

http://doi.org/10.9770/jssi.2020.9.J(5)

Table 6. R-square

\begin{tabular}{|l|l|}
\hline & R Square \\
\hline MSP & 0.881 \\
\hline SP & 0.861 \\
\hline SSP & 0.482 \\
\hline
\end{tabular}

The blindfolding procedure is opted to determine the predictive ability of our study. The blind folding results are shown in the figure 3 and table 7 below.

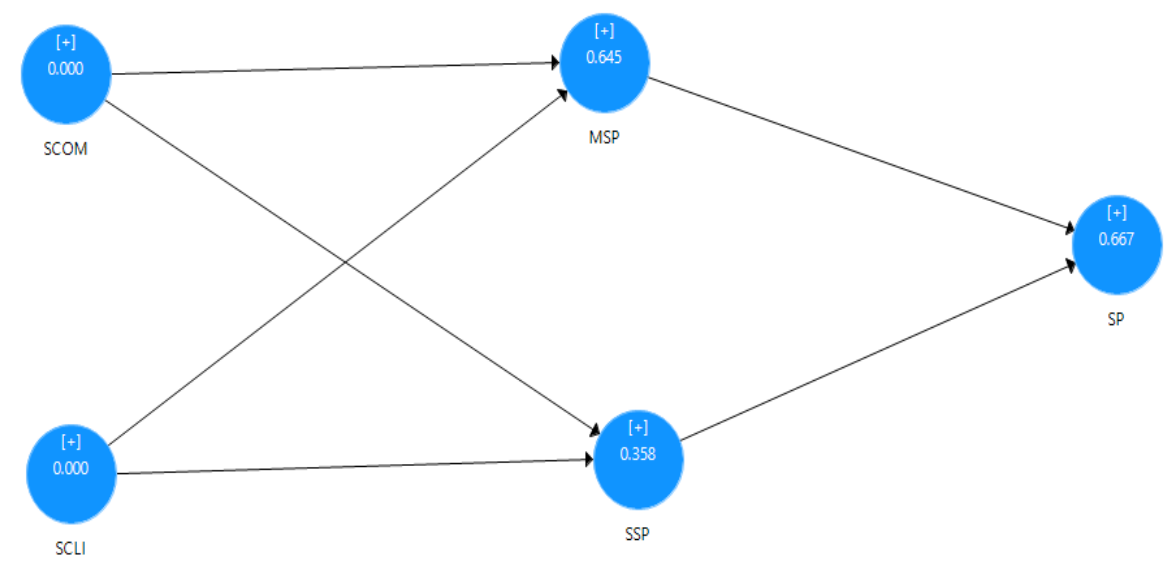

Figure 3. Blindfolding

The results in the table 7 are showing that Q-square value of all the factor sis non-zero which indicates that there is no issue of predictive ability

Table 7. Q-square

\begin{tabular}{|l|l|l|l|}
\hline & SSO & SSE & $\mathbf{Q}^{2}(=\mathbf{1}$-SSE $/$ SSO) \\
\hline MSP & $1,085.000$ & 385.596 & 0.645 \\
\hline SCLI & $1,085.000$ & $1,085.000$ & \\
\hline SCOM & $1,302.000$ & $1,302.000$ & \\
\hline SP & 868.000 & 289.344 & 0.667 \\
\hline SSP & $1,085.000$ & 696.820 & 0.358 \\
\hline
\end{tabular}

\section{Conclusion}

It was found by using partial least square method is opted and findings revealed that there is a significant association between management safety practices and the explanatory variables other than safety attitude. The findings reveal that management safety practice is a crucial variable of safety climate that can influence other explanatory variables. The use of extensive practices for safety management by the employer can ensure the consistency of safety training. Moreover, it can create safety awareness among the employees at different levels such as officer, co-worker, supervisor, and manager. 


\section{JOURNAL OF SECURITY AND SUSTAINABILITY ISSUES ISSN 2029-7017/ISSN 2029-7025 (online) 2020 Volume 9 January http://doi.org/10.9770/jssi.2020.9.J(5)}

The employees' behavior, which improves their personal health and safety, is represented by safety compliance. The behavior of employees in a way, which improves the health and safety of co-workers along with support for the objectives and goals are represented by safety participation. Major compliance refers to comply with equipment for personal protection before starting work and throughout work. These safety practices are the responsibility of employees for reducing the chances of occupational accidents. Safety behavior is contributed by careless working behavior. Therefore, it may influence safety performance. For instance, to complete a specific task in a short time, safety instructions can be ignored by workers. The situation has become even worse as the foreign workers are employed in almost every sector. It is suitable to analyze the safety climates, which affect the safety performance between industry operators of emulsifiers in Thailand. These companies are exposed to different hazards in routine.it is observed that the tremendous changes have been brought in organizational safety by intense competition across the globe and advancements in technology. However, a negative influence can be made on the organizational productivity by these changes. A big attention has been received by safety performance at workplace in several countries. However, huge cost is associated with safety maintenance at workplace.

\section{References}

Albrecht, S. L., Bakker, A. B., Gruman, J. A., Macey, W. H., \& Saks, A. M. (2015). Employee engagement, human resource management practices and competitive advantage: An integrated approach. Journal of Organizational Effectiveness: People and Performance, 2(1), 7-35. https://doi.org/10.1108/JOEPP-08-2014-0042

Barbaranelli, C., Petitta, L., \& Probst, T. M. (2015). Does safety climate predict safety performance in Italy and the USA? Cross-cultural validation of a theoretical model of safety climate. Accident Analysis \& Prevention, 77, 35-44. https://doi.org/10.1016/j.aap.2015.01.012

Bernardi, A. (2019). The capability approach and organizational climate as tools to study occupational health and safety, Insights into Regional Development 1(2): 155-169. https://doi.org/10.9770/ird.2019.1.2(6)

Beus, J. M., McCord, M. A., \& Zohar, D. (2016). Workplace safety: A review and research synthesis. Organizational psychology review, 6(4), 352-381. https://doi.org/10.1177\%2F2041386615626243

Buruck, G., Dörfel, D., Kugler, J., \& Brom, S. S. (2016). Enhancing well-being at work: The role of emotion regulation skills as personal resources. Journal of Occupational Health Psychology, 21(4), 480. https://doi.org/10.1037/ocp0000023

Cañamares, M. S., Escribano, B. V., García, M. G., Barriuso, A. R., \& Sáiz, A. R. (2017). Occupational risk-prevention diagnosis: A study of construction SMEs in Spain. Safety science, 92, 104-115. https://doi.org/10.1016/j.ssci.2016.09.016

Carayon, P., Hancock, P., Leveson, N., Noy, I., Sznelwar, L., \& Van Hootegem, G. (2015). Advancing a sociotechnical systems approach to workplace safety-developing the conceptual framework. Ergonomics, 58(4), 548-564. https://dx.doi.org/10.1080\%2F00140139.2015.1015623

Casey, T., Griffin, M. A., Flatau Harrison, H., \& Neal, A. (2017). Safety climate and culture: Integrating psychological and systems perspectives. Journal of Occupational Health Psychology, 22(3), 341. https://doi.org/10.1037/ocp0000072

Chen, Y., McCabe, B., \& Hyatt, D. (2017). Impact of individual resilience and safety climate on safety performance and psychological stress of construction workers: a case study of the Ontario construction industry. Journal of Safety Research, 61, 167-176. https://doi.org/10.1016/j.jsr.2017.02.014

Cooper, D., \& Schindler, P. (2008). International edition: business research methods. New Delhi: MacGraw-Hill.

Curcuruto, M., \& Griffin, M. A. (2018). Prosocial and proactive "safety citizenship behaviour" (SCB): The mediating role of affective commitment and psychological ownership. Safety Science, 104, 29-38. https://doi.org/10.1016/j.ssci.2017.12.010 


\section{JOURNAL OF SECURITY AND SUSTAINABILITY ISSUES ISSN 2029-7017/ISSN 2029-7025 (online) 2020 Volume 9 January http://doi.org/10.9770/jssi.2020.9.J(5)}

Dobrzykowski, D. D., McFadden, K. L., \& Vonderembse, M. A. (2016). Examining pathways to safety and financial performance in hospitals: A study of lean in professional service operations. Journal of Operations Management, 42, 39-51. https://doi.org/10.1016/j.jom.2016.03.001

Duarte, P. A. O., \& Raposo, M. L. B. (2010). A PLS model to study brand preference: An application to the mobile phone market Handbook of partial least squares (pp. 449-485): Springer. https://doi.org/10.1007/978-3-540-32827-8 21

Fang, D., Wu, C., \& Wu, H. (2015). Impact of the supervisor on worker safety behavior in construction projects. Journal of Management in Engineering, 31(6), 04015001. https://doi.org/10.1061/\%28ASCE\%29ME.1943-5479.0000355

Fernández-Muñiz, B., Montes-Peón, J. M., \& Vázquez-Ordás, C. J. (2017). The role of safety leadership and working conditions in safety performance in process industries. Journal of Loss Prevention in the Process Industries, 50, 403-415. https://doi.org/10.1016/j.jlp.2017.11.001

Gefen, D., Straub, D., \& Boudreau, M.-C. (2000). Structural equation modeling and regression: Guidelines for research practice. Communications of the association for information systems, 4(1), 7. https://doi.org/10.17705/1CAIS.00407

Griffin, M. A., \& Curcuruto, M. (2016). Safety climate in organizations. Annual Review of Organizational Psychology and Organizational Behavior, 3, 191-212. https://dx.doi.org/10.1146/annurev-orgpsych-041015-062414

Hair, J. F., Black, W. C., Babin, B. J., \& Anderson, R. E. (2010). Multivariate data analysis: Global edition: Pearson Higher Education Upper Saddle River, NJ.

Hair Jr, J. F., Hult, G. T. M., Ringle, C., \& Sarstedt, M. (2016). A primer on partial least squares structural equation modeling (PLS-SEM): Sage publications.

Henseler, J., Ringle, C. M., \& Sarstedt, M. (2012). Using partial least squares path modeling in advertising research: basic concepts and recent issues. Handbook of research on international advertising, 252.

Hofmann, D. A., Burke, M. J., \& Zohar, D. (2017). 100 years of occupational safety research: From basic protections and work analysis to a multilevel view of workplace safety and risk. Journal of Applied Psychology, 102(3), 375. https://doi.org/10.1037/apl0000114

Hu, J., Erdogan, B., Jiang, K., Bauer, T. N., \& Liu, S. (2018). Leader humility and team creativity: The role of team information sharing, psychological safety, and power distance. Journal of Applied Psychology, 103(3), 313. https://doi.org/10.1037/apl0000277

Huang, Y.-H., Lee, J., McFadden, A. C., Murphy, L. A., Robertson, M. M., Cheung, J. H., \& Zohar, D. (2016). Beyond safety outcomes: An investigation of the impact of safety climate on job satisfaction, employee engagement and turnover using social exchange theory as the theoretical framework. Applied ergonomics, 55, 248-257. https://doi.org/10.1016/j.apergo.2015.10.007

Hurtado, D. A., Kim, S. S., Subramanian, S., Dennerlein, J. T., Christiani, D. C., Hashimoto, D. M., \& Sorensen, G. (2017). Nurses' but not supervisors' safety practices are linked with job satisfaction. Journal of nursing management, 25(7), 491-497. https://doi.org/10.1111/jonm.12484

Jermsittiparsert, K., Sriyakul, T., Sutduean, J., \& Singsa, A. (2019). Determinants of Supply Chain Employees Safety Behaviours. Journal of Computational and Theoretical Nanoscience, 16(7), 2959-2966. https://doi.org/10.1166/jctn.2019.8202

Jitwasinkul, B., Hadikusumo, B. H., \& Memon, A. Q. (2016). A Bayesian Belief Network model of organizational factors for improving safe work behaviors in Thai construction industry. Safety science, 82, 264-273. https://doi.org/10.1016/j.ssci.2015.09.027

Kayes, D. C. (2015). Organizational resilience: How learning sustains organizations in Crisis, disaster, and breakdown: Oxford University Press, USA.

Lu, C.-S., \& Kuo, S.-Y. (2016). The effect of job stress on self-reported safety behaviour in container terminal operations: The moderating role of emotional intelligence. Transportation research part F: traffic psychology and behaviour, 37, 10-26. https://doi.org/10.1016/j.trf.2015.12.008

Montella, A., \& Imbriani, L. L. (2015). Safety performance functions incorporating design consistency variables. Accident Analysis \& Prevention, 74, 133-144. https://doi.org/10.1016/j.aap.2014.10.019 


\section{JOURNAL OF SECURITY AND SUSTAINABILITY ISSUES ISSN 2029-7017/ISSN 2029-7025 (online) 2020 Volume 9 January http://doi.org/10.9770/jssi.2020.9.J(5)}

Mullen, J., Kelloway, E. K., \& Teed, M. (2017). Employer safety obligations, transformational leadership and their interactive effects on employee safety performance. Safety Science, 91, 405-412. https://doi.org/10.1016/j.ssci.2016.09.007

Najjar, S., Nafouri, N., Vanhaecht, K., \& Euwema, M. (2015). The relationship between patient safety culture and adverse events: a study in Palestinian hospitals. Safety in Health, 1(1), 16. https://doi.org/10.1186/s40886-015-0008-Z

Ogundipe, K. E., Ogunde, A., Olaniran, H. F., Ajao, A. M., Ogunbayo, B. F., \& Ogundipe, J. A. (2018). Missing gaps in safety education and practices: academia perspectives. International Journal of Civil Engineering and Technology (IJCIET), 9(1), $273-289$.

Reinhold, K., Järvis, M., Prause, G. (2019). Occupational health and safety aspects of green shipping in the Baltic Sea. Entrepreneurship and Sustainability Issues, 7(1), 10-24. http://doi.org/10.9770/jesi.2019.7.1(1)

Robinson, P. R. (2017). Safety and the Environment Springer Handbook of Petroleum Technology (pp. 85-147): Springer.

Robson, L. S., Clarke, J. A., Cullen, K., Bielecky, A., Severin, C., Bigelow, P. L., . . Mahood, Q. (2007). The effectiveness of occupational health and safety management system interventions: a systematic review. Safety science, 45(3), 329-353. https://doi.org/10.1016/j.ssci.2006.07.003

Smith, T. D., Eldridge, F., \& DeJoy, D. M. (2016). Safety-specific transformational and passive leadership influences on firefighter safety climate perceptions and safety behavior outcomes. Safety science, 86, 92-97. https://doi.org/10.1016/j.ssci.2016.02.019

Smith, T. D., Hughes, K., DeJoy, D. M., \& Dyal, M.-A. (2018). Assessment of relationships between work stress, work-family conflict, burnout and firefighter safety behavior outcomes. Safety Science, 103, 287-292. https://doi.org/10.1016/j.ssci.2017.12.005

Vandekerkhof, P., Steijvers, T., Hendriks, W., \& Voordeckers, W. (2018). Socio-emotional wealth separation and decision-making quality in family firm TMTs: The moderating role of psychological safety. Journal of Management Studies, 55(4), 648-676. https://doi.org/10.1111/joms.12277

Vredenburgh, A. G. (2002). Organizational safety: which management practices are most effective in reducing employee injury rates? Journal of safety research, 33(2), 259-276. https://doi.org/10.1016/S0022-4375(02)00016-6

Wehbe, F., Al Hattab, M., \& Hamzeh, F. (2016). Exploring associations between resilience and construction safety performance in safety networks. Safety science, 82, 338-351. https://doi.org/10.1016/j.ssci.2015.10.006

Wu, X., Liu, Q., Zhang, L., Skibniewski, M. J., \& Wang, Y. (2015). Prospective safety performance evaluation on construction sites. Accident Analysis \& Prevention, 78, 58-72. https://doi.org/10.1016/j.aap.2015.02.003

Xu, X., Payne, S. C., \& Bergman, M. E. (2018). The measurement equivalence of a safety climate measure across five faultlines. Accident Analysis \& Prevention, 121, 321-334. https://doi.org/10.1016/j.aap.2018.05.011

Yang, L.-Q., Zheng, X., Liu, X., Lu, C.-q., \& Schaubroeck, J. M. (2019). Abusive supervision, thwarted belongingness, and workplace safety: A group engagement perspective. Journal of Applied Psychology. https://psycnet.apa.org/doi/10.1037/apl0000436

Yovi, E. Y., \& Nurrochmat, D. R. (2018). An occupational ergonomics in the Indonesian state mandatory sustainable forest management instrument: A review. Forest Policy and Economics, 91, 27-35. https://doi.org/10.1016/j.forpol.2017.11.007

Zhou, Z., Goh, Y. M., \& Li, Q. (2015). Overview and analysis of safety management studies in the construction industry. Safety science, 72 , 337-350. https://doi.org/10.1016/j.ssci.2014.10.006 


\section{JOURNAL OF SECURITY AND SUSTAINABILITY ISSUES ISSN 2029-7017/ISSN 2029-7025 (online) 2020 Volume 9 January http://doi.org/10.9770/jssi.2020.9.J(5)}

Thammarak SRIMARUT is a Lecturer of Suan Sunandha Rajabhat University, Thailand. His research areas are Industrial Technology, Safety Technology, and Occupational Health.

Witthaya MEKHUM is an Associate Professor and the Vice President for Planning and Quality Assurance of Suan Sunandha Rajabhat University, Thailand. His research areas are Industrial Technology, Security Management, and Material Management.

ORCID ID: orcid.org/0000-0002-9667-3730

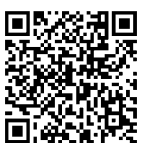

Register for an ORCID ID:

https://orcid.org/register

This work is licensed under the Creative Commons Attribution International License (CC BY).

http://creativecommons.org/licenses/by/4.0/

cc) (7) Open Access 